\title{
The year of the monkey and of global understanding
}

\author{
Koen Martens
}

Published online: 23 November 2015

(C) Springer International Publishing Switzerland 2015

Life is evolution and with evolution comes change. The concept of change is basic to the science of both evolution and ecology, the two major fields of aquatic research that are in the scope of Hydrobiologia. We are now 15 years after the "dawn" of our new century, and what changes have we seen in our journal itself? Quite a lot I would say! The world of scientific publishing is changing at ballistic speeds, what with online submission and reviewing systems, online and Open Access publishing, search and indexing machines, various metrics that emerged over the past years and now compete with the ISI Impact Factor, etc. Thanks to the Springer staff that is responsible for Hydrobiologia, these changes were absorbed seamlessly and Hydrobiologia surfs on the waves of progress (pun intended).

In addition to these worldwide technical changes, Hydrobiologia also saw its position amongst other scientific journals increase. Over the last 10 years, our ISI Impact Factor grew faster than other journals in our field, from 0.653 to 2.275 , and so did our ISI ranking, which now puts us in the first quartile (Q1) of the section "Marine and Freshwater Biology". Other metrics show similar trends. How did this success come about? For sure, the implementation of the

K. Martens ( $\square)$

Royal Belgian Institute of Natural Sciences, Operational Directorate Natural Environment, Brussels, Belgium e-mail: martens@naturalsciences.be above-mentioned technical platforms has significantly increased the visibility of the journal. As an example only, Hydrobiologia is now online available on 10 million desktops worldwide! Surely that must count for something!

Nevertheless, I think part of the magic was in the changes that we implemented in the editorial structure, expertise and handling of the review process. Since 2003, when I took over as Editor in Chief, we have progressively professionalized our editorial work. We have enlarged the boards of associate and advisory editors. We use several criteria to invite editors: the need to cover a certain subject area of Hydrobiologia, the quality of the editor within that area, representation of gender and geographic spread of editors. Hydrobiologia now has about 40 associate editors covering a wide range of research areas in marine and freshwater biology and ecology. Each editor handles manuscripts in his/her field, finds the most appropriate referees and makes expert suggestions to improve manuscripts. Our biannual editorial board meetings bring editors physically together for a few days, which allows us to discuss editorial matters, but (even more importantly I think) allows editors to get to know each other. And this creates a team of editors, who exchange points of view and learn from each other. Our Brazilian editors coined the slogan: "we wear the T-shirt!". (soccer fans will immediately understand...).

Brilliant special issues have resulted from such meetings and new research collaborations have 
emerged. This synergy makes that the editors of Hydrobiologia have a common vision as to what the journal is and where we want to go to. Part of that vision is that we want Hydrobiologia to be truly international, reaching out into all continents, including Antarctica, and beyond! Another part is that we are ready to invest time and effort in helping authors from less favoured regions to prepare their manuscripts for an international journal. This is a conditio sine qua non to become a Hydrobiologia editor. All of the above, I think, has made a difference.

But life continues to evolve and so does the editorial work at Hydrobiologia. In 2013, the increasing inflow of submitted manuscripts made it impossible for one person to oversee it all and Luigi Naselli-Flores from Palermo (Italy) became Associate Editor in Chief, taking over a very considerable chunk of the final decisions in the manuscript flow. His contribution made a huge difference. But now, only 3 years later, even the two of us cannot handle things anymore without jeopardizing the efficiency and quality of the manuscript review process. So more changes were necessary. And I am now proud to announce that two more Associate Editors in Chief have been appointed, namely Diego Fontaneto (also from Italy) and Sidinei M. Thomaz (from Brazil). These three AEiC, already known as the three musketeers of Hydrobiologia (does that make me D'Artagnan?), will divide the final decisions in manuscript flow amongst them. Roughly speaking, Luigi will supervise our editors that handle freshwater ecology papers, Diego will supervise marine and molecular editors and Sidinei will oversee the special issues. I thank these gentlemen for their willingness and efforts to further improve the standing of Hydrobiologia in aquatic biology and ecology. Short CV's and pictures of the Hydrobiologia musketeers are at the end of this editorial.

2016 will be the Year of the Monkey according to the Chinese zodiac. According to the "chinahighlights" website, the years of the monkey are especially productive for people with a career in science. This is duly noted.

But 2016 is also the International Year of Global Understanding (IYGU-http://www.globalunderstanding.info/). The IYGU programme will deal with aspects of global change, knowledge transfer and the science/policy interface. In all of these fields, Hydrobiologia has already played a role and will continue to do so. The editors of Hydrobiologia wish to contribute to the IYGU, just as we did during the International year of Biodiversity. We hope that the new editorial structure will allow us to interact with this and other initiatives that seek to improve the understanding of aquatic biology and ecology in an even more efficient and direct way.

Hydrobiologia will work for Global Understanding in 2016 and beyond!

Koen Martens

Editor in Chief 


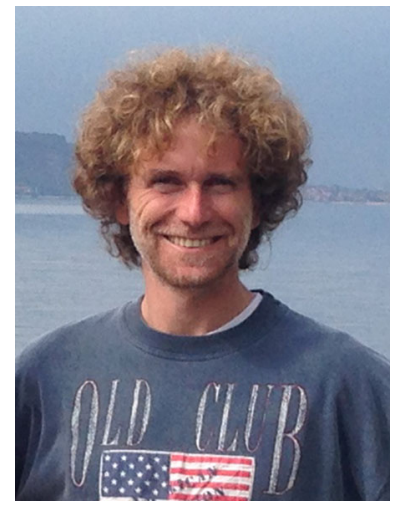

Diego Fontaneto is a zoologist and an ecologist interested in biological diversity in general, and in particular in how bdelloid rotifers can survive, persist and diversify in the apparent absence of sexual recombination. Given the ubiquity of bdelloids in any habitat, from freshwater to marine, to their unusual ecological characteristics of desiccation resistance, and to their 'scandalous' evolutionary features of being considered ancient asexuals, his work is often at the boundary between ecology and evolution. In 2012 he joined the editorial board of Hydrobiologia and was exposed to an even wider diversity of approaches and ideas through the manuscripts that he has handled since then.

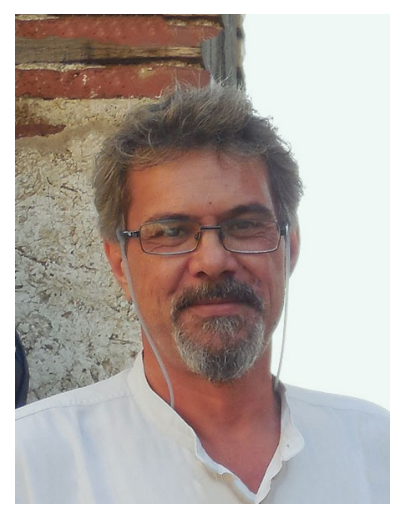

Luigi Naselli-Flores is a hydrobiologist, mainly interested in freshwater phytoplankton and its taxonomic and ecological classification systems. He is also intrigued by the effects of environmental constraints on size and shape of planktic algae and, more recently, by the mechanisms allowing microorganisms to disperse across different freshwater ecosystems. He is a Professor of Plant Ecology at the University of Palermo since 2007; in the same year he was asked to join the Hydrobiologia editorial team as Associate Editor. Since then, his "scientific horizons" had to widen in order to deal with the huge diversity of manuscripts submitted to the journal. In 2013, he started serving as Associate Editor in Chief.

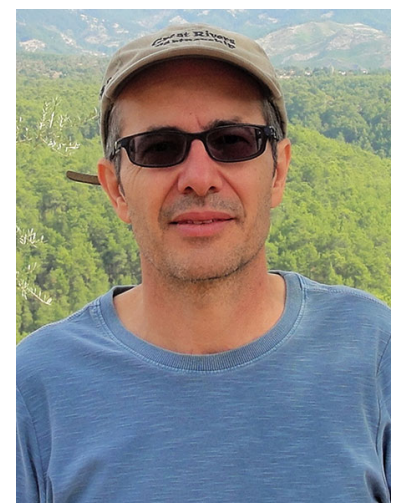

Sidinei Thomaz is a biologist currently teaching at the State University of Maringá, Brazil. He uses aquatic macrophytes and related organisms to test ecological concepts about biological invasions and biodiversity. He also has a special interest in ecology of large river-floodplain ecosystems. He likes combining observational and experimental research to understand the beautiful field of aquatic ecology. The former (observational) is conducted mainly in the Upper Paraná River floodplain and the latter (experimental) in a greenhouse at his university. He jointed the editorial board of Hydrobiologia in 2004. Science takes most of his life, but during his spare time, he appreciates arts (mainly paintings) and red wine. 